\title{
A New Model for Training on Human Specimens in Surgical-Anatomical Skills Labs
}

\author{
HP Theeuwes ${ }^{1,2 *}$, MPJM van Riel ${ }^{1}$, JF Lange ${ }^{1,3}$ and GJ Kleinrensink ${ }^{1}$ \\ ${ }^{1}$ Department of Neuroscience-Anatomy, Erasmus University Medical Centre, Netherlands \\ ${ }^{2}$ Department of Surgery, Zuyderland Hospital, Netherlands \\ ${ }^{3}$ Department of Surgery, Erasmus University Medical Centre, Netherland
}

Submission: July 07, 2017; Published: July 18, 2017

*Corresponding author: HP Theeuwes, Department of Neuroscience-Anatomy, Erasmus University Medical Centre Rotterdam, P.0. Box 2040, 3000, Rotterdam, Netherlands, Tel: +31-6-18112401; Fax: +31-10-7043257; Email: hilcotheeuwes@gmail.com

\begin{abstract}
Introduction: Surgical-anatomical training on human specimens is one of the aspects for medical education, more specific surgical education. Before these specimens can be used for educational purposes they need to be preserved. There are different methods preserving human remains for those donated their body to science. Formaldehyde embalming is most frequently used and is well suited for learning and teaching gross anatomy. Learning anatomy related to surgical procedures on embalmed bodies is rather difficult because of the rigidity after fixation. This new method makes it possible to fixate human bodies for years but without the usual disadvantages of rigidity. It is made possible to perform and teach all kind of surgical interventions. The rigidity of the wrist was used to compare the differences in flexibility between nonembalmed, normally embalmed and bodies embalmed with this new method.
\end{abstract}

Materials and Method: Conventional formalin embalmed arms and arms embalmed with our new method were compared with fresh frozen (non-embalmed) arms. Force measurements were performed on single, embalmed, undissected arms. The used size for rigidity of the wrist was the force needed to start flexion (movement) of the hand, Newton Metre, to reach a predefined angle.

Results: In total nineteen human arms were measured. The arms embalmed with the new method showed comparable results with the non-embalmed arms upon 30 degrees of wrist flexion. Fresh frozen arms remain more flexible above 15 degrees of wrist flexion compared with both groups. In 30 degrees and more, the formalin embalmed arms showed significantly higher rigidity when compared with the new method embalmed arms.

Conclusion: The results show a significant decrease in joint stiffness of the wrist in the NCA embalmed bodies when compared with conventional formalin embalmed bodies. Although the flexibility is not the same when compared with non-embalmed bodies, the benefits of this new method are useful in performing surgical interventions and the making of dynamic anatomical models on a larger scale without the disadvantages of fresh frozen or 'light' embalmed specimen. The method described to measure the flexibility of the wrist can be used as a calibrated instrument to give value to the flexibility after and before embalming.

\section{Introduction}

Embalming human bodies is of all times, after the introduction of formaldehyde fixation for organic tissues in 1893 by the German physician Ferdinand Blum, the donated bodies could be used more efficiently for gross anatomy purposes than before Fox et al. [1]. Nowadays the demand for (embalmed) human bodies used for surgical training, besides normal anatomy teaching, has increased. Mostly fresh frozen human bodies, donated for science, are used for surgical trainings. Its realistic tissue handling and flexibility represent the main advantages of fresh frozen human bodies. The disadvantages however are also well known: risk of infection (additional testing is essential), degeneration, time pressure and single use are only some examples. The introduction of "light" or "soft' embalming methods like Thiel's, Duke's or other new method'shave contributed to prolonging the natural characteristics of the donated bodies Thiel et al. [2-8]. All of these methods have made it possible to re-use embalmed bodies for multiple purposes. It is now possible to use the bodies more efficiently because they can be used multiple times. These new methods slow down the degeneration process for weeks without losing their natural characteristics. Still these methods were not developed for long time fixation and conservation of human flexible characteristics. 
Methods developed for long-term embalming and the remaining of flexibility like Complucador Anubi are less well known.

In our institution multiple methods have been tried, but none of these methods had the capacity of remaining for H.P. Come he bodies sufficiently flexible and stopped the degeneration of the bodies completely. A tour around most of our anatomical departments in the Netherlands confirmed our findings. Since the demand of flexible bodies for surgical training increased we started our search for developing a new embalming method that would guaranty enough fixation to stop the degeneration process, but would remain the near normal flexibility characteristics of the body. At Erasmus MC, the University Medical Centre Rotterdam, a large university hospital with an internationally oriented surgical training centre, the demand for fresh frozen bodies increased over the years. Since these bodies only last for one or two days after thawing, the capacity for training surgical residents decreased over time. For specialised courses, research and educational purposes as a rule only fresh frozen body-parts are used instead of complete bodies. Usually refreezing of the unused parts is an inferior option since the tissues continue to degenerate. Embalming with formaldehyde, phenol or alcoholglycerine fixation can prevent this process. However, the main disadvantages of these methods are the increased tissue stiffness and the lack of colour preservation. We developed a new embalming agent, in the article referred to as: New Conditioning Agent (NCA), a combination of a novel pre-rinse formula plus formalin embalming. With this new embalming agent the embalmed human bodies are less stiff when compared with the standard formalin method. In a previous publication by our research group 'proof of principle' was shown with regard to endoscopic procedures. However no data could be published about the objectively measured flexibility of the joints, which in our perspective is of great importance in surgical training and functional research of the locomotor system.

The aim of this study was to objectively show this advantage under standardized experimental conditions. We compared two embalming methods, formaldehyde and NCA, with the "gold standard", i.e. fresh frozen human bodies, with regard to mechanical tissue aspects (rigidity). Not many experiments have been conducted to measure the flexibility of embalmed human bodies. Since the flexibility of the joints and tissue quality is of great importance for performing surgical interventions we introduce a new method for measuring joint flexibility. Instead of only using a standard protractor, also the force needed to do so was also taken into account. The wrist-joint movement was chosen since:

a. This is an easily accessible joint.

b. The measurements could be controlled and repeated easily. c. This joint was amply available in our laboratory. Furthermore, this joint has been reported in other papers and hence comparison with previous data was easier.

Last but not least the wrist joint is of clinical/surgical importance. Because of the complexity of the anatomy and the trauma treatment of this delicate joint complex, training of surgical techniques during hand-wrist courses in the dissection room becomes more and more important.

\section{Materials and Method}

\section{Embalming}

Bodies from deceased persons who donated their body for education and science at our institution were embalmed at room temperature between 24-48 hours post-mortem. Embalming was regularly performed via two annuals fixated in the right femoral artery, one in cranial direction ('up stream') and one in caudal direction ('down stream'). A perfusion pressure of $150 \mathrm{mmHg}$ was used. After perfusion, the human bodies were immersed in a $4,4 \%$ formaldehyde solution for at least four months (described in more detail in experiment section), the latter to ensure thorough fixation of the skin and intestinal organs. After this period the fixated human bodies were transferred for at least two months to a conservation container, and immersed in a $1 \%$ phenoxy-ethanol solution. The human bodies remain immersed in these containers until they are needed for research or education purposes.

\section{Experiment}

Two embalming methods were compared with nonembalmed "fresh frozen" human arms. The first method: using a $4,4 \%$ formaldehyde ( $11 \%$ formalin) embalming solution, consists of $0,2 \mathrm{M}$ phosphate buffer $\left(\mathrm{pH}_{7}, 4-7,6\right), 1000$ grams $\mathrm{Na}_{2} \mathrm{SO}_{4} \bullet 10 \mathrm{H}_{2} \mathrm{O}, 500$ grams $\mathrm{NaCl}, 10$ litres of $86.5 \%$ glycerol, 6 litres $37 \%$ formaldehyde and replenished with Millia water to a total of 50 liters. The second (experimental) method: NCA embalming is a combination of a novel pre-rinse formula plus a $4,4 \%$ formaldehyde embalming solution, as described in the first method. After admission of the pre-rinse solution, a 30 minutes incubation interval was added followed by light manipulation of the skin and flexion of the joints. Embalming was furthermore performed as described above in the embalming section. In total, six (3 left, 3 right) 4,4\% formaldehyde embalmed and eight NCA (5 left, 3 right) embalmed arms were compared with five fresh frozen arms (1 left, 4 right). The formaldehyde group consisted of three left and three right arms from four different bodies (1 female, 5 males; mean age 83:SD7). The second NCA group consisted of five left and three right arms from five different bodies ( 6 females, 2 males; mean age 80:SD14). For the fresh frozen group four right and one left arm were available from three different bodies ( 5 females; mean age 82:SD15). 


\section{Measurements}

Single, embalmed, un-dissected (detached) arms were fixated in a setup with Velcro straps (Figure 1). The proximal parts of the arms were fixated in a semi-circular plastic pipe, with the arms positioned in supination (volar side directed upwards). The hand was strapped on a Plexiglas board. The Plexiglas board had a length of $25 \mathrm{~cm}$ and weighted 675 grams. A stainless steel (traction) wire was attached to the board and guided through the centre of a small whole $5 \mathrm{~cm}$ above the board, ensuring an upward directed force that was continuously perpendicular to the Plexiglas board (Figure 1). The other end of the wire was connected to a force transducer. For all measurements the distance between the rotation axis and the point of application of the force was $25 \mathrm{~cm}$. A measure for the stiffness of the wrist is the force needed to start flexion (movement) of the hand. We measured the forces at predefined angles; 0, 15, 30, 45, 60 and 75 degrees. Before every measurement the hand was positioned in the predefined angle on the Plexiglas board with a protractor. The protractor was adjusted before each measurement to indicate the right corresponding angles.

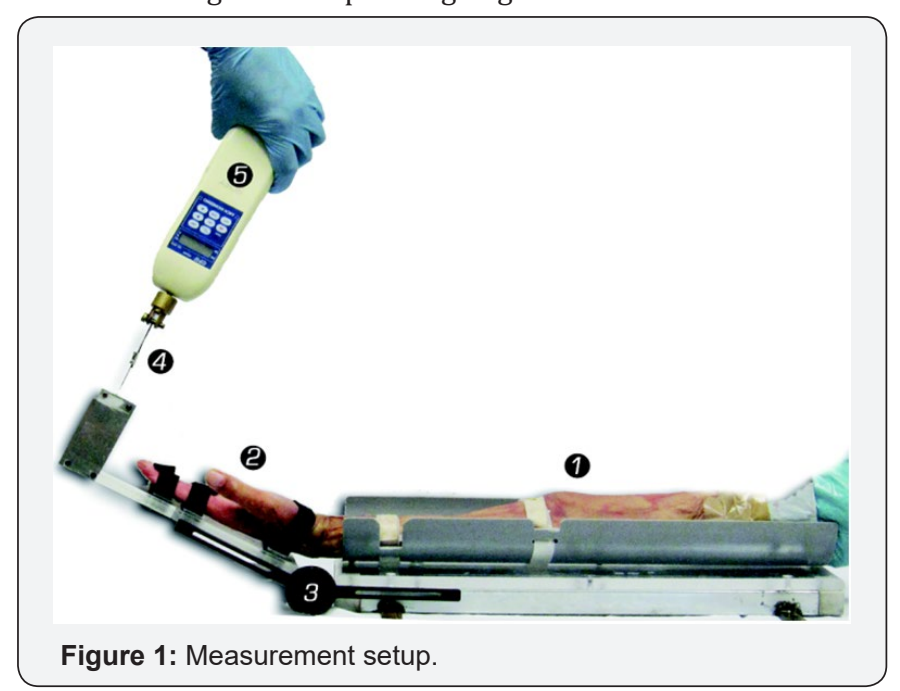

1. Fixation of the arm, 2. Fixation hand on the Plexiglas board, 3. Protractor (attached for illustration purposes) 4. Traction wire, 5. CPU digital force gauge transducer.

\section{Biomechanical approach}

The rotational stiffness is defined as the applied moment for one degree of rotation. Figure 2 give a schematic overview to visualize the corresponding forces and the torque of these forces. The force needed to start rotating the hand $\left(\mathrm{F}_{\text {pull }}\right)$ was the force needed to lift the hand $\left(\mathrm{F}_{\text {hand }}\right)$ and Plexiglas board $\left(\mathrm{F}_{\text {board }}\right)$ and necessarily to exceed the rotational stiffness of the wrist. The moment arm (c) of this force was constant in al measurements $(=25 \mathrm{~cm}$ ) because the pulling force was always perpendicular to the Plexiglas board. In the situation that the wrist joint was an ideal joint without any friction then $\mathrm{F}_{\text {pull }}$ could be calculated by:

$$
\mathrm{F}_{\text {pull }} \cdot \mathrm{c}=\mathrm{F}_{\text {board }} \cdot \mathrm{b} \cdot \cos (\alpha)+\mathrm{F}_{\text {hand }} \cdot \mathrm{a} \cdot \cos (\alpha)
$$

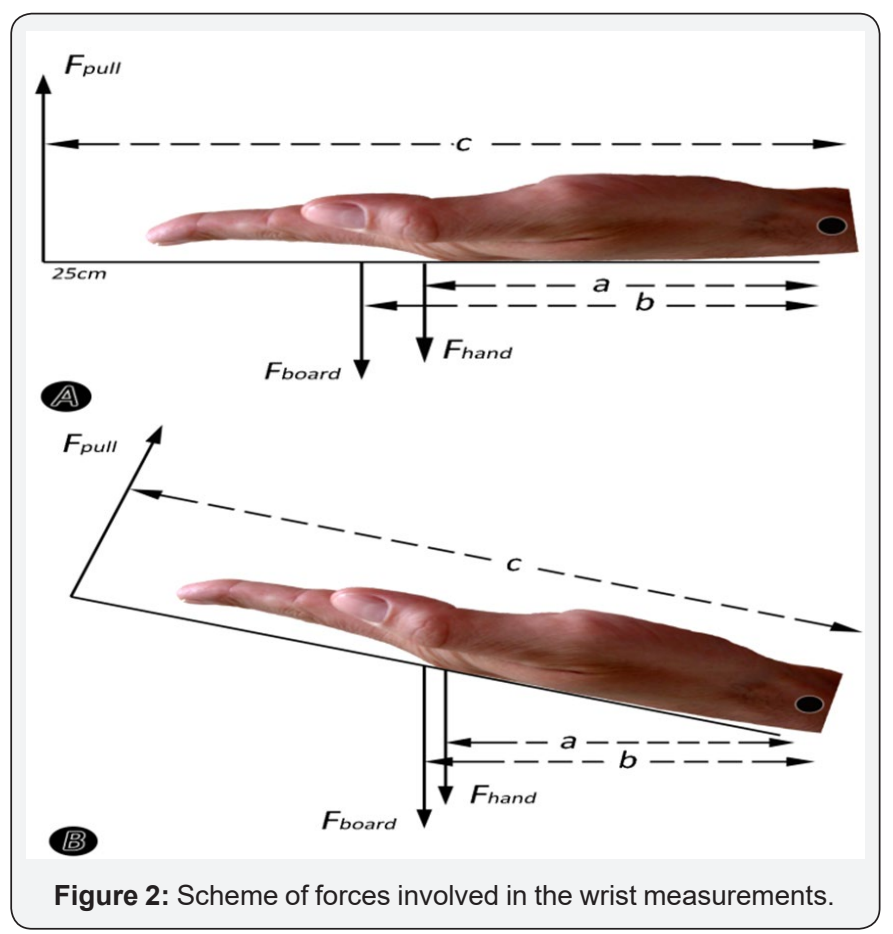

If there was a certain resistance against rotation in the joint because of stiffness in the wrist then an extra moment $\left(\mathrm{M}_{\text {stiffness }}\right)$ would have to be overcome. In that situation the pulling force would be:

$$
\mathrm{F}_{\text {pull }} \cdot \mathrm{c}=\mathrm{F}_{\text {board }} \cdot \mathrm{b} \cdot \cos (\alpha)+\mathrm{F}_{\text {hand }} \cdot \mathrm{a} \cdot \cos (\alpha)+\mathrm{M}_{\text {stiffness }}
$$

Since the body weight of the different bodies was not known in our experiment an average value of the weight of the hand, the mass of the hand $(0,4 \%$ of total body weight from an estimated 80 kilograms) and the position of the centre of gravity of the hand in relation to the wrist joint were found in Chaffin [9]. DINED Anthropometric database. Standard values of the mass of the hand and the distance to the rotation axis in the wrist joint are given in Table 1.The force was measured with a commercially available force transducer (AIKOH CPU digital force gauge, 9000 series 50kgf, Aikoh engineering Co. LTD, Osaka, Japan). The peak-hold function of the force transducer was used in order to measure the highest force needed to start the motion. The maximal angle of 75 degrees was chosen in order to avoid anatomical limitations to the motion.

\section{Data analysis}

The means were compared using Mann-Whitney's U test. Multi-variant regression analysis was used to test the influence of gender and side on the moments needed for flexion of the wrists. The embalming technique was put in the model as dummy variable. 


\section{Results}

In total nineteen human arms were measured from twelve different bodies. The average forces $( \pm \mathrm{SD}$ ) needed to flexion the wrist at different angles are presented for NCA, formaldehyde embalmed bodies and for fresh frozen bodies (Table 1). With the newly developed embalming liquid NCA the pulling force was in all positions significantly lower when compared to the forces needed in the arms embalmed with formaldehyde, except at the zero degrees position. As can be seen in (Figure 3), the pulling$$
\text { zero degrees position. As can be seen in (Figure } 3 \text { ), the pulling }
$$

Table 1: The mean pulling force in NCA, formalin and non-embalmed bodi force needed in the NCA group was statistically significant higher when compared to fresh frozen bodies except in the positions at zero and fifteen degrees. Figure 3 shows the average force corrected for the weight of the hand and the weight of the Plexiglass board. The fresh frozen bodies showed no significant increase or decrease in force needed to flex the wrist during the experiments. A significantly lower force was needed to flex the arms at $30^{\circ}, 45^{\circ}, 60^{\circ}$ and $75^{\circ}$ in favour of the NCA (purple line) when compared with conventional (formalin) embalming (red line). No significant difference was observed at $0^{\circ}$ and $15^{\circ}$.

\begin{tabular}{|c|c|c|c|c|c|c|}
\hline & $\begin{array}{c}\text { Formaldehyde } \\
\mathbf{n = 6}\end{array}$ & & NCA n-8 & & $\begin{array}{c}\text { Fresh } \\
\text { Frozen(ref) } \mathbf{n = 5}\end{array}$ \\
\hline Degrees & Mean & SD & Mean & SD & Mean & SD \\
\hline 0 & 0,00 & 0,39 & 0,16 & 0,24 & 0,26 & 0,22 \\
\hline 15 & 0,77 & 0,42 & 0,53 & 0,20 & 0,37 & 0,21 \\
\hline 30 & 3,91 & 0,76 & $0,90+$ & 0,34 & 0,40 & 0,18 \\
\hline 45 & 6,92 & 1,28 & $1.40+$ & 0,39 & 0,44 & 0,21 \\
\hline 60 & 6,45 & 1,47 & $2,85+$ & 0,54 & 0,56 & 0,31 \\
\hline 75 & 9,11 & 1,39 & $4,81+$ & 1,38 & 1,02 & 0,62 \\
\hline
\end{tabular}

Both groups needed significantly more force to move the wrist at $30^{\circ}, 45^{\circ}, 60^{\circ}$ and $75^{\circ}$ when compared with the fresh frozen, reference group (yellow line), see 1). The embalmed bodies with the NCA were two/ three times more flexible than the formaldehyde embalmed bodies. The traditionally embalmed bodies were 50 till $60 \%$ stiffer when compared to NCA embalming. Multi-variant regression analysis between groups for gender $(p=0,782)$ and side $(p=0,782)$ did not differ significantly.

\section{Discussion}

Training on fresh frozen bodies is the method of choice in most surgical training situations. However, several major disadvantages make this a model, which cannot be used in a setting in which large quantities are needed, i.e. in an international training centre or shortage of freezers. To test whether a new method of embalming could be an alternative or complementary for fresh frozen bodies, flexibility experiments were performed on fresh frozen anatomical specimen and the results were compared with the results of tests on formaldehyde embalmed and NCA prepared bodies. For which a new, specific, measurement tool was developed. When compared to formalinembalmed bodies, NCA bodies showed a significantly higher flexibility.

In Figure 3 is shown that NCA embalmed bodies were two to three times more flexible than formalin-embalmed specimen. Although the colour preservation and hence the problem of discrimination between structures were not mentioned in this paper, it is generally known that anatomical structures in embalmed bodies can be differentiated less easy than in vivo or in fresh frozen specimen. This of course is due to loss of colour, which in turn is due to loss of erythrocytes and the embalming process itself. NCA has the tendency to be more realistic than formalin embalming regarding colour and tissue handling. Presently we are conducting experiments in which we add colorants to solve this problem.

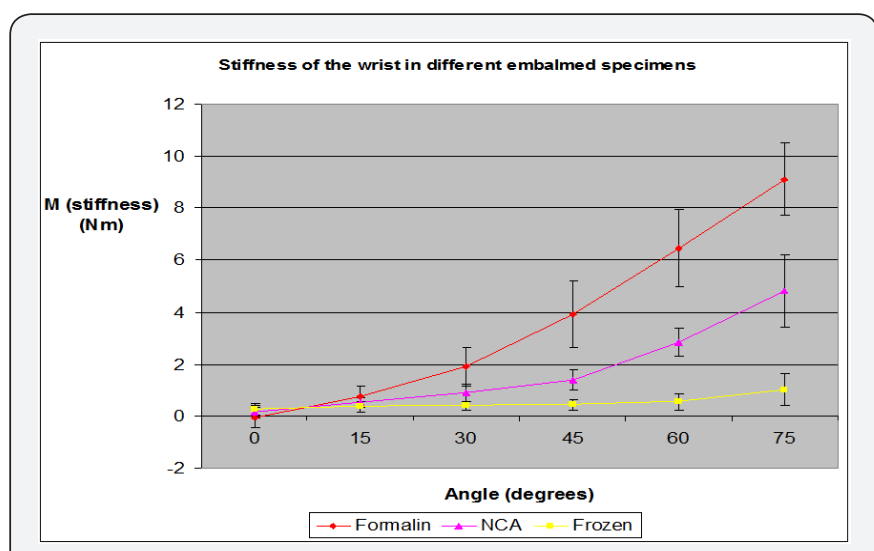

Figure 3: Torque needs for rotation of the hand at different angles for several prepared human bodies.

In our department of anatomy there is an increasing demand for postgraduate (surgical) education, mainly with regard to teaching and training of new surgical techniques; application of prosthesis, fracture management and laparoscopic operations. One of the main advantages besides flexibility is the ample, quick and easy availability of flexible, embalmed human bodies. In case of serious specific pathology quick and easy replacement of a body is an advantage, which cannot be underestimated. The conventional formalin embalming method can still be used 
for standard dissection courses, which mainly focuses on static study of gross anatomy. In our institution fresh frozen bodies were usually used for courses regarding the human locomotor system and abdominal interventions.

NCA embalmed human bodies however have successfully replaced fresh frozen bodies at our institution. Furthermore the systemic perfusion with NCA also increases the quality of brain tissue, making brain surgery interventions possible, which could not be performed before, e.g. certain skull base approaches. An increasing demand for new and realistic (laparoscopic) surgicalanatomical training facilities have encouraged us to continue exploring new applications with this new promising method Slieker et al. [10], Klitsie et al [11]. Currently we are conducting a study in which no formalin is being used, first results are promising Brenner [12], Hayashi S [13].

\section{Conclusion}

The results show a significant decrease in joint stiffness of the wrist in the NCA embalmed bodies when compared with conventionally (formaldehyde) embalmed bodies. Even though the NCA embalmed bodies did not fully meet the flexibility of 'gold standard', i.e. fresh frozen bodies, it remains a remarkable improvement compared with the standard formalin embalming method. Taken into account that these bodies can be conserved for several years without losing their specific characteristics and will not decay, the NCA preservation method can be considered a useful alternative or complementary method to fresh frozen bodies in the anatomy and surgical training labs. Especially for those institutions or countries not using freezers. The method described to measure the flexibility of the wrist can be used as a calibrated instrument to give value to the flexibility after and before embalming.

\section{Acknowledgment}

The authors would like to thank: the people and their next of kin for donating their bodies for science at our NeuroscienceAnatomy Department making this research possible. Ms Yvonne Steinvoort, prosector, for extended help during the embalming process. Tim de Jong, MD, PhD. for his assistance on the data analysis and table presented in this article, Alex Poublon and Ante Prkic for their assistance on the data acquisition and all members of the EARP-student team (www.earprotterdam.nl) for their effort and enthusiasm during this project.

\section{References}

1. Fox CH, Johnson FB, Whiting J, Roller PP (1985) Formaldehyde fixation. J Histochem Cytochem 33(8): 845-853.

2. Thiel W (1992) An arterial substance for subsequent injection during the preservation of the whole corpse. Ann Anat 174(3): 197-200.

3. Thiel W (1992) The preservation of the whole corpse with natural color. Ann Anat 174(3): 185-195.

4. Thiel W (2002) Supplement to the conservation of an entire cadaver according to W Thiel. Ann Anat 184(3): 267-269.

5. Anderson SD (2006) Practical light embalming technique for use in the surgical fresh tissue dissection laboratory. Clin Anat 19(1): 8-11.

6. Krekel PR, de Bruin PW (2009) Evaluation of bone impingement prediction in pre-operative planning for shoulder arthroplasty. Proc Inst Mech Eng H 223(3): 813-822.

7. Messmer C, Kellogg RT, Zhang Y (2010) A technique to perfuse cadavers that extends the useful life of fresh tissues: the Duke experience. Anat Sci Educ 3(4): 191-194

8. Jaung R, Cook P, Blyth P (2011) A comparison of embalming fluids for use in surgical workshops. Clin Anat 24(2): 155-161.

9. Chaffin DB, Andersson G (1984) Occupational biomechanics, Fourth Edition ed. New York: Wiley Complucad. 2001 Complucad anatomic In Spain pp. 365.

10. Slieker JC, Theeuwes HP, van Rooijen GL (2012) Training in laparoscopic colorectal surgery: a new educational model using specially embalmed human anatomical specimen. Surg Endosc. 26(8):2189-94.

11. Klitsie PJ, Ten Brinke B, Timman R (2017) Training for endoscopic surgical procedures should be performed in the dissection room: a randomized study. Surg Endosc 31(6): 1754-1759.

12. Brenner E (2014) Human body preservation - old and new techniques. J Anat 224(3): 316-344.

13. Hayashi S, Naito M, Kawata S, Qu N, (2016) History and future of human cadaver preservation for surgical training: from formalin to saturated salt solution method. Anat Sci Int 91(1): 1-7.

\begin{tabular}{l} 
Your next submission with Juniper Publishers \\
will reach you the below assets \\
- Quality Editorial service \\
- Swift Peer Review \\
- Reprints availability \\
- E-prints Service \\
- Manuscript Podcast for convenient understanding \\
- Global attainment for your research \\
- Manuscript accessibility in different formats \\
( Pdf, E-pub, Full Text, Audio) \\
- Unceasing customer service \\
Track the below URL for one-step submission \\
https://juniperpublishers.com/online-submission.php \\
\hline
\end{tabular}

